\title{
Factors associated with a fantastic lifestyle in Brazilian college students - a multilevel analysis
}

\author{
Rafael Aiello Bomfim(1) \\ Maynara Azevedo Silva Mafra(1) \\ lad Muhamad Samih Gharib ${ }^{(1)}$ \\ Alessandro Diogo De-Carli(1) \\ Edilson José Zafalon(1)
}

\begin{abstract}
(1) Universidade Federal de Mato Grosso do Sul - UFMS - Cidade Universitária, Campo Grande- MS - Brazil.
\end{abstract}

Conflict of interest: Nonexistent

Received on: December 21, 2016 Accepted on: August 1, 2017

Mailing address: Rafael Aiello Bomfim

Av Senador Fillinto Muller s/n - Campo Grande, MS, Brasil

CEP: 79070-900

E-mail: aiello.rafael@gmail.com

\section{ABSTRACT}

Purpose: to analyze possible associations between a Fantastic lifestyle and self-perception of oral health, binge drinking, and socio-demographic variables among public college students.

Methods: questionnaires validated for use in Brazil were applied to 672 students in randomly selected courses. It was the first questionnaire to assess a Fantastic lifestyle, the second to measure oral health-related quality of life (OHIP-14), and the third to include socio-demographic information. Multilevel linear regression was used for the analyses.

Results: among the participants, $64.21 \%$ were full-time students, $52.82 \%$ were females, $50.85 \%$ had a family income between 4 and 8 minimum wages, $16.75 \%$ were binge drinkers, and $22.22 \%$ used to drive after drinking. Socio-demographic variables such as income $(p=0.001)$, religion $(p=0.02)$, marital status $(p=0.021)$, binge drinking $(p<0.001)$, and OHIP-14 $(p<0.001)$ were associated with a Fantastic lifestyle.

Conclusions: fantastic lifestyle of the Brazilian college students was associated with income, oral health-related quality of life, marital status, religion, and alcohol consumption (binge drinking).

Keywords: Oral Health; Lifestyle; Binge Drinking 


\section{INTRODUCTION}

The Lalonde report (1974) in Canada recognized lifestyle (LS) as one of the main factors for social determination of health ${ }^{1}$, which can lead to a great loss of years of life and high expenses with health services ${ }^{2}$. Health promotion is seen as the main strategy for the reduction of morbidity and mortality, reinforcing actions on people's LS, since many diseases (e.g., hypertension, diabetes, cancer) are consequences of harmful behaviors, such as stress, inadequate feeding, and consumption of psychoactive substances ${ }^{3}$, and a significant percentage of non-communicable diseases could thus be avoided ${ }^{4}$. Nevertheless, LS has no particular definition, it is related to habits, and it can be influenced by or developed during daily work or study activities ${ }^{5}$.

Studies have demonstrated the benefits of healthy LS as a protective factor for the physical and mental health of university students ${ }^{6,7}$. The university way of life represents a complex stage in which habits and behaviors play a decisive role for the rest of life. In addition to constant psychological changes at this stage, one takes on responsibility for one's own health ${ }^{5}$ and there is greater access to alcoholic beverages ${ }^{8}$. This leads to bingedrinking - episodic excessive use of alcohol ${ }^{9-12}$. According to the U.S. National Institute on Alcohol Abuse and Alcoholism (NIAAA), the amount that defines binge drinkingis the consumption of five or more doses of alcoholic beverages on a single occasion, but ${ }^{13}$ dosesgive a serious cause for concern${ }^{14}$ because of the practice of unsafe sex, greater susceptibility to physical violence, and mainly because 1.8 to $2.2 \%$ of individuals usually drive after bingedrinking ${ }^{15}$.

In the alignment of the investigations about the influences of LS on the health-disease process, the FANTASTIClifestyle questionnaire $(F L S)^{16}$ has been used in a promising way, given the multiple issues it addresses.

Bearing in mind the scope of the current concept of health, oral health should be inserted in the context of LS, since it is also influenced by socioeconomic and behavioral factors. For the comprehension of the healthdisease process and considering the perspective that oral health is related to social determinants of health, it is necessary to further explore this issue in specific populations, such as university students, as such approaches can influence general health ${ }^{17}$ and the capacity for work ${ }^{18}$ and can be measured using an instrument validated for use in Brazil - the short-form Oral Health Impact Profile (OHIP-14) ${ }^{19}$.
Thus, when we consider Brazil as a country with continental dimensions, characterized by remarkable social inequalities, it is necessary that SUS (Unified Health System), represented here by student assistance services provided by public educational institutions, meet heterogeneous demands ${ }^{20}$. This need is heightened when, nowadays, access to college education is available to people from different social strata, made possible by inclusive policies established by the federal government. These different social strata imply greater heterogeneity among university students $-a$ recent fact in the academic community ${ }^{20}$.

Through the use of the FLS questionnaire, based on the specific information provided, this study is expected to support the actions of multi-professional health teams (composed of nurses, dentists, physicians, physical therapists, speech therapists, among others).To adopt a trans-disciplinary approach in a specific community, favoring the development of more effective therapeutic projects ${ }^{21}$, Latin American studies ${ }^{22}$ have been investigatingFANTASTIC Lifestyle (FLS) of university students. This was the first study carried out to verify the possible associations between FLS, OHRQoL, binge drinking, and socio-demographic characteristics of Brazilian students from a public university. The hypothesis of the study to be tested is that FANTASTIC lifestyle is associated with OHRQoL, binge drinking, and sociodemographic characteristics of university students.

\section{METHODS}

This is a cross-sectional, observational study with students $(n=672)$ from a public universityconducted from August 2015 to August 2016.

\section{Inclusion criteria}

For the selection of the courses, their proportional sizes were accounted for, pre-selecting them from the areas of physical, human, and biological/health sciences with more vacancies made available for the night and day shifts by the Unified Selection System (SISU). The courses not included in the pre-selection were randomly selected through a draw.

\section{Exclusion criteria}

Technical courses and those with less than usual training time, such as those with 3 years' training, were excluded. 


\section{Pilot study and sample size calculation}

A pilot study was undertaken with 15 students from each area (physical, human, and biological sciences), totaling 45 students, who did not participate in the research itself, in order to know the FLS score among the students for the study design (minimization of possible biases) and sample size calculation.

Significant differences were found between first- and last-year students, allowing for important adjustments in the sample selection. In order to minimize possible bias, we divided the students to match the distribution by grouping each course into three categories (1st- and 2nd-semester students, 2nd- and $3^{\text {rd }}$-year students (3rd to 6th semesters), and students in the 4th and 5th grades (7th to 10th semesters), using the same proportion of students among the respective categories in order to estimate the FLS average score. For each course, there was the same number of students in the three categories defined previously, which were representative of all phases and categories.

The sample size was then calculated by the t-test, with a power of $90 \%$ and alpha of $5 \%$. The calculation took into account the FLS average scores and the standard deviation and was performed in the Stata v.14 software (College Corp, TX, USA), corresponding to the initial participation of 530 students in the research. After considering $10 \%$ of losses and $15 \%$ of study design effects, the final sample eventuallyincluded 672 students.

\section{Application of the questionnaires}

Before the beginning of the research and after obtaining authorization from the professors, two researchers explained the research objectives to the participants for approximately $5 \mathrm{~min}$. After that, the students were randomlyselected according to the list available from the Siscad / UFMS management system printed by the professor. After agreeing to their participation, students, individually and independently answered the questionnaires validated for use in Brazil and the socio-demographic questionnaire as well.

The questionnaires consisted of close-ended questions: one containing socio-demographic variables, another one in which self-perception of oral health was evaluated, and the Oral health impact profile - OHIP-14, which evaluates OHRQoL in seven domains, ranging from 0 (best oral health status) to 56 points (worst oral health status), validated for use in Brazil by Oliveira and Nadanovsky ${ }^{19}$.
FANTASTIC lifestyle, validated by Anez et al.16, originates from the acronym FANTASTIC, i.e., initial letters of the nine domains into which the items are distributed: $F=$ Family and friends; $A=$ Activity (physical activity); $N=$ Nutrition; $T=$ Tobacco \& toxic substances (cigarettes and drugs); $\mathrm{A}=$ Alcohol; $\mathrm{S}=$ Sleep, seatbelts, stress, safe sex; $\mathrm{T}=$ Type of behavior; behavioral pattern A or B; I = Insight; and C = Career (satisfaction with the profession). This questionnaire contained 25 questions - 23 had five possible answers and two were dichotomous questions. The sum of all points allowed classifying individuals into five categories, namely: excellent (85 to 100 points),very good (70 to 84 points),good (55 to 69 points),regular (35 to 54 points), and in need ofimprovement (0 to 34 points).

\section{Dependent and independent variables}

The dependent variable was the FLS score, which was represented by the gross value of the questionnaires.

The independent variables were dichotomized or categorized in order to assess whether the coefficients were statistically significant in relation to the dependent variable. The independent variables were the following: course area (physical, human,or biological sciences), study shift (morning, afternoon, and full shift), gender (female or male), housing (living alone / with partner, parents, in a dorm),race (white and non-white), family income (up to 3 , between 4 and 8 , and above 9 minimum wages), religion (Catholic and other), religion practitioner (yes/no), athletic association participation (yes/no), marital status (single, single but in a stable relationship, or married), bingedrinking (yes/no), OHIP-14 (questionnaire score), and age group (up to 21 years and above 21 years).

\section{Statistical analysis}

The obtained data were inserted into anExcel ${ }^{\circledR}$ spreadsheet and analyzed by STATA ${ }^{\circledR}$ v.14. The means, proportions, and confidence intervals were calculated, as well as multilevel linear regressions with mixed effects for the analysis of the dependent variable (FANTASTIC Lifestyle score), considering that the levels of the courses (17 participating courses) were considered as a second-level variable and the individual variables as a first-level variable, since both course load and the proposed activities can influence students' responses at the individual level. The regression 
analysis used a blockwise selection, with the analysis of all independent variables, i.e., it was adjusted by all the independent variables present in the model.

\section{Ethical aspects}

The research project was approved by the Research Ethics Committee of the Federal University of Mato Grosso do Sul (UFMS), process number CAAE 124416 / 2015-2.

\section{RESULTS}

A total of 672 (355 female and 317 male) students participated in the study. Reliability was satisfactory for both questionnaires, with Cronbach's alpha values ${ }^{23}$ of 0.72 for the FLS score and 0.87 for OHIP-14, respectively. The mean age was 22.5 years with a standard deviation of 5 years. The average FLS and OHIP-14 scores were 68.47 and 9.29, respectively, considering the participants with a good lifestyle and a satisfactory oral health status. Note that the standard deviation was 10.97 for FLS and 7.86 for OHIP-14 and that the confidence interval $(\mathrm{Cl})$ comprises the estimated interval on which the average of a parameter has a given probability of occurring.

There was a higher prevalence of female $(52.86 \%)$ and Catholic (47.44\%) students, and $59 \%$ of them said they were religion practitioners. In addition, there was a predominance of students living with their parents $(64.49 \%)$, with an average income of 4 to 8 minimum wages $(50 \%)$,and parents with afull university degree (43.87\%). Most students attended a partial or full shift $(62.79 \%)$ and $60.77 \%$ reported not participating in athletic associations or in university games. Among the participants, $22.22 \%$ reported driving after drinking (Table 1).

According to the FLS classification of the studied population, $42.49 \%$ had a goodLS and $42.19 \%$ had a very good LS, and $9.06 \%$ considered their lifestyle asregularand $0.44 \%$ reported they needed to improve it.

Table 2 presents the multilevel linear regression analysis with mixed effects, where the dependent variable was the FLS score. The independent variables such as income $(p=0.001)$, religion $(p<0.02)$, marital status (single but in a stable relationship $(p<0.021)$ or married $(p<0.001))$, and the OHIP-14 score $(p<0.001)$ were significantly associated with the FLS score, that is, the better the participant's perception of oral health, the better the positive association.

The data in Table 3 show most courses had an average score for similar FANTASTIC lifestyle; however, civil engineering was the course with the highest average (73.5), whereasmedicine had the lowest score $(64,07)$. The analysis of variance showed statistically significant differences between courses $(p=0.01$ ), as well as prevalence of bingedrinking. Note that the medical course had the highest prevalence (35.71\%).

\section{DISCUSSION}

FLS evaluation among Brazilian undergraduate students is still scarce and, therefore, the present study makes a major contribution by evaluating FLS and self-perception of oral health in 17 undergraduate courses of a federal university, despite the fact that some studies ${ }^{5,7,8}$ demonstrated persistently low quality of life among medical students compared to students in other courses. This can be explained by extremely stressful training, study time requirements, in addition to contact with patients and with deaths, which can cause depressive symptoms among students and may interfere in the quality of life of thesefuture professionals ${ }^{24,25}$. These studies on the quality of life of university students corroborate the findings of the present research, given that medical undergraduates had the lowest FLS average when compared with students in other courses. Rodrigues-Añez et al. (2008) ${ }^{16}$ found similar results when they evaluated 62 undergraduate and graduate students (mean age of 21.3 years), among whom $21 \%$ scored between 55 and 69 points (good) and $61.3 \%$ scored between 70 and 84 points (very good), corroborating the findings of the present research. Compared with students from other countries, the study conducted with Colombian university students ${ }^{21}$ showed significant differences in the FLS score between men and women, which was not verified in our study.

Alcohol consumption deserves special attention as it has a potential influence on FLS. As for undesirable events (accidents, violence, personal injury) associated with alcohol consumption, our study revealed $16.75 \%$ of college students have already indulged in bingedrinking, that is, consumed five or more alcoholic drinks at the same time. Our findings are in agreement with those of Cardoso et al. ${ }^{8}$, since those authors report that $15.3 \%$ of students in health sciences yield to 
Table 1. Distribution of independent variables $(n=672)$

\begin{tabular}{|c|c|c|c|}
\hline \multirow{2}{*}{$\begin{array}{c}\text { Variables } \\
\text { Area }\end{array}$} & \multirow[t]{2}{*}{$\mathrm{n}(\%)$} & \multicolumn{2}{|c|}{$95 \% \mathrm{Cl}$} \\
\hline & & & \\
\hline Human & 233(34.72) & 31.14 & 38.49 \\
\hline Physical & $177(26.35)$ & 23.09 & 29.9 \\
\hline Biological & $262(38.93)$ & 35.21 & 42.74 \\
\hline \multicolumn{4}{|l|}{ Shift } \\
\hline Morning & $107(15.96)$ & 13.33 & 19.01 \\
\hline Evening & $1(0.15)$ & 0.08 & 0.28 \\
\hline Night & $132(19.68)$ & 16.79 & 22.94 \\
\hline Full & $432(64.21)$ & 58.98 & 66.44 \\
\hline \multicolumn{4}{|l|}{ Gender } \\
\hline Female & $355(52.86)$ & 48.99 & 56.7 \\
\hline Male & $317(47.14)$ & 42.98 & 50.69 \\
\hline \multicolumn{4}{|l|}{ Housing } \\
\hline Living alone/with partner & $203(30.23)$ & 26.8 & 33.89 \\
\hline Living with parents & $433(64.49)$ & 60.73 & 79.08 \\
\hline Living in a dorm & $36(5.28)$ & 3.65 & 7.11 \\
\hline \multicolumn{4}{|l|}{ Parent's schooling } \\
\hline Full secondary education or higher & $563(83.80)$ & 80.81 & 86.40 \\
\hline Incomplete secondary education & $109(16.20)$ & 13.59 & 19.18 \\
\hline \multicolumn{4}{|l|}{ Race } \\
\hline White & $400(59.53)$ & 55.68 & 63.26 \\
\hline Non-white & $272(40.47)$ & 36.73 & 44.31 \\
\hline \multicolumn{4}{|l|}{ Income } \\
\hline Up to 3 minimum wages & 188(28.06) & 24.71 & 31.66 \\
\hline 4 to 8 minimum wages & $342(50.85)$ & 46.98 & 54.7 \\
\hline 9 or more minimum wages & $142(21.09)$ & 18.01 & 24.41 \\
\hline \multicolumn{4}{|l|}{ Religion } \\
\hline Catholic & $319(47.44)$ & 43.6 & 51.31 \\
\hline Other & $353(52.56)$ & 48.7 & 54.18 \\
\hline \multicolumn{4}{|l|}{ Religion practitioner } \\
\hline No & $274(40.77)$ & 37.03 & 44.62 \\
\hline Yes & $398(59.23)$ & 55.23 & 63.91 \\
\hline \multicolumn{4}{|l|}{ Athletic association participation } \\
\hline No & $409(60.77)$ & 56.93 & 64.48 \\
\hline Yes & $263(39.23)$ & 35.38 & 44 \\
\hline \multicolumn{4}{|l|}{ Marital status } \\
\hline Single & $387(57.67)$ & 53.81 & 61.44 \\
\hline Married/living with partner & $68(10.07)$ & 79.75 & 12.65 \\
\hline Stable relationship & $217(32.26)$ & 28.74 & 35.96 \\
\hline \multicolumn{4}{|l|}{ Binge drinking } \\
\hline Yes & $112(16.75)$ & 14.05 & 19.83 \\
\hline
\end{tabular}


606 | Bomfim RA, Mafra MAS, Gharib IMS, De-Carli AD, Zafalon EJ

Table 2. Multilevel linear regression analysis of FANTASTIC lifestyle and other independent variables $(n=672)$

\begin{tabular}{ccccc}
\hline Variables & $\boldsymbol{\beta}$ & $\mathbf{9 5 \%} \mathbf{C l} \boldsymbol{\beta}$ & $\boldsymbol{p}$ \\
\hline Age group & 0.21 & $-1,19$ & 1.61 & 0.77 \\
Areas & 0.44 & -0.50 & 1.39 & 0.36 \\
Shift & 0.92 & -1.09 & 2.94 & 0.36 \\
Gender & 0.98 & -0.63 & 2.6 & 0.234 \\
Housing & -1.42 & -4.98 & 2.13 & 0.433 \\
Parent's schooling & 0.08 & -2.03 & 2.20 & 0.93 \\
Race & 0.69 & -0.91 & 2.31 & 0.39 \\
Income & 1.29 & 0.49 & 2.08 & 0.001 \\
Religion & 0.005 & -0.56 & 0.57 & 0.98 \\
Religious practitioner & 1.85 & 0.22 & 3.47 & 0.02 \\
Athletic association participation & 0.64 & -1.00 & 2.29 & 0.44 \\
Marital status & 0.99 & 0.14 & 1.83 & 0.021 \\
OHIP-14 & -0.39 & -0.49 & -0.29 & $<0.001$ \\
Binge drinking & -9.33 & -11.46 & -7.19 & $<0.001$ \\
\hline Null model & Variation among courses & & $95 \% \mathrm{Cl}$ \\
Courses & \multicolumn{2}{c}{$2.14 \%$} & & $0.4 \%-9.51 \%$ \\
\hline
\end{tabular}

Multilevel linear regression with mixed effects

Log-likelihood $=-2402.96$

Prob $>\mathrm{Xi}^{2}<0.0000$

Table 3. Mean and standard deviation of FANTASTIC lifestyle and prevalence ofbinge drinking $(n=672)$

\begin{tabular}{ccccc}
\hline Courses & $\mathbf{n}$ & Prevalence(\%) & FLS & SD \\
\hline Business administration & 87 & 18.39 & 68.87 & 10.19 \\
Architecture & 30 & 13.33 & 64.46 & 10.17 \\
Law & 85 & 17.64 & 69.42 & 13.27 \\
Nursing & 29 & 13.79 & 68.06 & 7.75 \\
Computer engineering & 28 & 14.28 & 71.46 & 9.81 \\
Environmental & 30 & 23.33 & 67.9 & 10.11 \\
engineering & 31 & 13.33 & 73.5 & 9.9 \\
Civil engineering & 28 & 19.35 & 68.54 & 9.37 \\
Electrical engineering & 29 & 3.42 & 68.89 & 9.71 \\
Production engineering & 3.44 & 69.89 & 10.05 \\
Physics & 30 & 13.33 & 67.23 & 10.41 \\
Physical therapy & 30 & 14.28 & 65.6 & 8.96 \\
Languages & 28 & 14.28 & 64.85 & 9.7 \\
Mathematics & 28 & 35.71 & 64.07 & 13.67 \\
Medicine & 42 & 23.33 & 68.76 & 7.99 \\
Dentistry & 30 & 12.24 & 67.95 & 13.3 \\
Pedagogy & 49 & 7.91 & 71.5 & 10.62 \\
Chemistry & 57 & 16.75 & 68.47 & 10.96 \\
Total & 672 & &
\end{tabular}

ANOVA for the FLS score $p=0.01$

Tukey's testfor differences among the courses 
bingedrinking, also corroborating the findings of Paul et al. $(2011)^{26}$, who estimated a prevalence of $15 \%$ for bingedrinking in the U.S. population. Therefore, alcohol consumption in this population has been a causefor concern and for the search of effective interventions for reducing consumption, as well as the problems and consequences associated with lifestyle ${ }^{27}$.

From this perspective, alcohol abuse has been found to be responsible for adverse consequences, such as heart and cerebrovascular diseases, fatal events, psychiatric disorders, as well as greater involvement in fights, especially among young people in the academic setting ${ }^{8}$. Another negative aspect of bingedrinking among undergraduates is that, because of such practice, they are more likely to perform poorly and neglect university activities, demonstrating that alcohol consumption may interfere with academic commitment and achievement $t^{8,24-28}$.

On the other hand, studies show that, despite the knowledge about the existing risks of bingedrinking, these young people continue to use alcohol for alleviation of stressful situations $\mathrm{s}^{8,29-32}$, rapid changesin the routine, and anxiety, and for the establishment of new friendships, as alcohol allows them to enter this new academic social environment, making them more susceptible to binge drinking $27,31,33$.

In the state of Rio Grande do Sul, Brazil, studies have revealed high alcohol consumption is more common among poorly educated and low-income individuals ${ }^{34}$, unlike the study conducted with individuals residing in Salvador, in the state of Bahia,which revealed that individuals who have a higherpurchasing power consume more alcoholic beverages ${ }^{35}$, corroborating the findings of our research.

Regarding the marital status of the participants in this study, those who were in a formal relationship (married, living with a partner) showed a better FLS than singles $(p<0.02)$, as singles are more often associated with fun involving alcoholic beverages and parties. Thus, it is clear that marital status can alter LS and impact the FLS score, considering that a stable marital status acts as a protective factor for lifestyle / inappropriate behavior ${ }^{5}$, also interfering with the risk of mortality, which can be as high as $25 \%$ in single individuals when compared with those living with their partners, as pointed out by an Italian cohort study ${ }^{26}$.

Religiousness also influences people's way of living because, through doctrines, faithful individuals are guided to behave in a healthy way, considering that by following religious precepts (practicing some religious orientation), individuals will presumably adopt healthy habits. Studies with adults have shown the importance given to religion is positively associated with quality of life in different contexts and can influence values, emotions, behaviors, and $\mathrm{LS}^{3}$. Having religious beliefs and a healthy behavior has been shown to be an individual empowerment factor ${ }^{3}$. Although this was not within the scope of our study, our findings are in agreement with other authors, since being a religious person interferes positively in the FANATASTIC lifestyle of university students $(p<0.001)$.

Income has also been reported to interfere with lifestyle, because of its influence on diet, housing, understanding, and healthcare, leading to direct exposure to the risk factors of various diseases ${ }^{26,36}$. In this study, income had a significant result, that is, the higher the purchasing power, the better the lifestyle of university students.

In 2003, studies by the World Health Organization (WHO) showed sociocultural and environmental factors influence oral health and quality of life ${ }^{4}$. Some studies have also shown poor oral health can limit daily activities ${ }^{37}$, impact $\mathrm{OHQoL}^{38}$, and influence ability to work $^{18}$. Our study demonstrated that the FLS score was positively associated with the OHRQoL score as measured by the OHIP-14 questionnaire. Thus, the idea that OHRQoL can influence FLS is reinforced, since those university students participating in this research had extensive course load and workload, prompting them to eat quickly and not regularly, thus impairing tooth brushing and flossing and eventually worsening their OHIP-14 scores.

Although there is positive evidence of well-being and physical activity, mostpeople do not follow an adequate routine ${ }^{26}$. As physical activity and eating habits play a significant role in health promotion and disease prevention, the data obtained by this study reinforce the idea that oral health status is directly related to quality of life.

The insertion of intervention and prevention actions targeted at improving the lifestyle of university students by reducing the percentage of alcohol consumption and, consequently, the practice of binge drinking, is then suggested. To do that, it is extremely important to implement health promotion activities in order to at least provide some reflection on LS and OHRQoL. These actions should be aimed at the recovery of university students with poor academic performance, based on the structuring of intrasectorial and intersectorial measures that give them support and urge them 
to take on commitmentto their academic performance and health.

Some limitations of the present study were evident. Because it is a cross-sectional study, factors associated with FLS cannot be interpreted as causal factors, but as factors associated with FLS. As the study was conducted in a single university, the results cannot be generalized to other university / population groups. Studies in private universities are thereforeneeded. In addition, considering self-administered questionnaires, a possible memory bias may have existed on the part of students. Also,whethera student was repeating a discipline or semester was not evaluated and this could invalidate the three categories used in sample selection. As the data were adjusted for age, this possible bias was minimized. However, the limitations do not compromise the results of the study, as multilevel analysis, which takes into account the context of the courses and adjusts the other individual independent variables, was used. In our pilot study, there was a different FLS pattern in academic semesters, which could be adjustedduring the research. This procedure validated our methodology and allowed us to compare courses more coherently. The reliability of the questionnaires was measured by Cronbach's alpha, whose values, to be satisfactory, should be above $0.7^{23}$.We obtained 0.72 and 0.87 for FLS and OHIP14 scores, respectively, demonstrating the reliability of the data.

Another limitation was the lack of quantification of the ingested alcohol doses, since bingedrinking was considered as the ingestion of five or more doses of alcoholic beverage without qualification of the type of drink and quantification of ingested alcohol amounts, which would also affect quality of life differently, with greater or lesser degrees of severity.

As future research perspectives, the association of alcoholic drinks and the amounts of alcohol ingested with FLS and quality of life should be investigated. In addition, longitudinal studies need to be performed with this target population to define causal directions between the analyzed variables, as well as to measure the impact of intervention measures and guidance for students on the outcomes of traffic accidents.

\section{CONCLUSIONS}

In conclusion,the FLS of Brazilian students from the public university assessed herein was associated with income, OHRQoL, marital status, religious practice, and binge drinking.

\section{REFERENCES}

1. Lalonde M. New perspective on the health of Canadians: 28 years later. Rev Panam Salud Publica. 2002;12(3):149-52.

2. Silva AMM, Brito IdS, Amado JMdC. Tradução, adaptação e validação do questionário Fantastic Lifestyle Assessment em estudantes do ensino superior. Cien Saude Colet. 2014;19(6):1901-9.

3. Soares M, Ferreira R, Pazzini C, Travassos D, Paiva S, Ferreira E. Individual and collective empowerment and associated factors among Brazilian adults: a cross-sectional study. BMC Public Health. 2015;15:775. doi: 10.1186/ s12889-015-2113-7.

4. Petersen P, Kwan S. The 7(th) WHO Global Conference on Health Promotion - towards integration of oral health (Nairobi, Kenya 2009). Community Dent Health. 2010;27(2):129-36.

5. Pacheco RL, Santos-Silva DA, Gordia AP, Bianchini de Quadros TM, Petroski EL. Sociodemographic determinants of university students' lifestyles. Rev Saude Publica. 2014;16(3):382-93.

6. González-Jiménez E, Schmidt-Río-Valle J, GarcíaLópez PA, García-García CJ. Análisis de la ingesta alimentaria y hábitos nutricionales en una población de adolescentes de la ciudad de Granada. Nutri Hosp. 2013;28(3):779-86.

7. Wang D, Ou C, Chen M, Duan N. Health-promoting lifestyles of university students in Mainland China. BMC Public Health. 2009;9:379. doi: 10.1186/1471-2458-9-379.

8. Cardoso FM, Barbosa HA, Costa FMd, Vieira MA, Caldeira AP. Factors associated with practice of binge drinking among students of health. Rev. CEFAC. 2015;17(2):475-84.

9. Arantes LFR. Binge drinking: um estudo bibliométrico (1999-2010) dos artigos publicados na base de dados SciELO. Estudos Psicol. 2012;29(2):253-7.

10. Oliveira $P$, Jorge $K$, Ferreira $E$, Ramos-Jorge $M$, Tataounoff J, Zarzar P. Association between dental trauma and alcohol use among adolescents. Dent Traumatol. 2013;29(5):372-7.

11. Cavariani MB, Oliveira JBd, Kerr-Corrêa F, Lima MCP. Expectativas positivas com o uso de álcool e o beber se embriagando: diferenças de gênero em estudo do Projeto GENACIS, São Paulo, Brasil. Cad Saude Publica. 2012;28(7):1394-404.

12. Meneses C, Markez I, Romo N, Uroz J, Rua A, Laespada T. Diferencias de género en el 
consumo diario de tabaco e intensivo de alcohol en adolescentes latinoamericanos en tres áreas españolas (Andalucía, Madrid y País Vasco). Rev Asoc Esp Neuropsiq. 2013;33(119):525-35.

13. NIAAA. Helping patients who drink too much: a clinician's guide. 2005.

14. Paiva PCP, Paiva HNd, Lamounier JA, Ferreira EFe, César CAS, Zarzar PM. Consumo de álcool em binge por adolescentes escolares de 12 anos de idade e sua associação com sexo, condição socioeconômica e consumo de álcool por melhores amigos e familiares. Cien Saude Colet. 2015;20(11):3427-35.

15. Moura EC, Malta DC, Morais Neto OL, Penna GO, Temporão JG. Motor vehicle driving after binge drinking, Brazil, 2006 to 2009. Rev Saude Publica. 2009;43(5):891-4.

16. Anez C, Reis R, Petroski E. Brazilian version of a lifestyle questionnaire: Translation and validation for young adults. Arq Bra Cardiol. 2008;91(2):102-9.

17. Brennan D, Teusner D. Oral health impacts on self-rated general and oral health in a crosssectional study of working age adults. Community Dent Oral Epidemiol. 2015;43(3):282-8.

18. Bomfim R, Crosato E, Mazzilli L. Relations between oral health and work ability among administrative workers. Braz J Oral Scien. 2015;14(1):41-5.

19. de Oliveira B, Nadanovsky P. Psychometric properties of the Brazilian version of the Oral Health Impact Profile-short form. Community Dent Oral Epidemiol. 2005;33(4):307-14.

20. Dutra NGR, Santos MFS. Assistência estudantil sob múltiplos olhares: a disputa de concepções. Ensaio: aval pol públ Educ. 2017;25(94):148-81.

21. Soleman C, Martins CL. The work of speech therapists under Support Centers for Family Health (NASF) - specificities of primary care. Rev. CEFAC. 2015;17(4):1241-53.

22. Ramirez-Velez R, Triana-Reina $H$, Carrillo $H$, Ramos-Sepulveda J, Rubio F, Poches-Franco L et al. A cross-sectional study of Colombian University students' self-perceived lifestyle. Springerplus. 2015;4:289. doi:10.1186/s40064-015-1043-2

23. Bland J, Altman D. Cronbach's alpha. British Medical Journal. 1997;314:572.

24. Bampi LNdS, Baraldi S, Guilhem D, Araújo MPd, Campos ACdO. Qualidade de vida de estudantes de medicina da Universidade de Brasília. Rev Bras Educ Med. 2013;37(2):217-25.
25. Enns M, Cox B, Sareen J, Freeman P. Adaptive and maladaptive perfectionism in medical students: a longitudinal investigation. Med Educ. 2001;35(11):1034-42.

26. Paul L, Grubaugh A, Frueh B, Ellis C, Egede L. Associations between binge and heavy drinking and health behaviors in a nationally representative sample. Addict Behav. 2011;36(12):1240-5.

27. Silva ÉC, Tucci AM. Intervenção breve para redução do consumo de álcool e suas consequências em estudantes universitários brasileiros. Psicologia: Reflexão e Crítica. 2015;28(4):728-36.

28. Guimarães VV, Florindo AA, Stopa SR, César CLG, Barros MBdA, Carandina $L$ et al. Consumo abusivo e dependência de álcool em população adulta no Estado de São Paulo, Brasil. Rev Bras Epidem. 2010;13(2):314-25.

29. Nunes JM, Campolina LR, Vieira MA, Caldeira AP. Consumo de bebidas alcoólicas e prática do binge drinking entre acadêmicos da área da saúde. Archiv Clinic Psychiatry. 2012;39(3):94-9.

30. Ocampo Ortega R, Bojorquez Chapela I, Unikel Santoncini C. Disordered eating behaviors and binge drinking in female high-school students: the role of impulsivity. Salud mental. 2012;35(2):83-9.

31. Setlalentoa M, Ryke E, Strydom $H$. The influence of binge drinking on social support networks. Social Work. 2014;50(3):349-70.

32. Loch MR, Souza RKTd, Mesas AE, Martinez-Gómez D, Rodríguez-Artalejo F. Relationship between social capital indicators and lifestyle in Brazilian adults. Cad Saude Publica. 2015;31 (8):1636-47.

33. Peuker AC, Fogaça J, Bizarro L. Expectativas e beber problemático entre universitários. Psic.: Teor. e Pesq. 2006;22(2):193-200.

34. Silveira CM, Silveira CC, Silva JGd, Silveira LM, Andrade AGd, Andrade LHSGd. Epidemiologia do beber pesado e beber pesado episódico no Brasil: uma revisão sistemática da literatura. Archiv Clinic Psychiatry. 2008;35(suppl 1):31-8.

35. Almeida-Filho N, Lessa I, Magalhães L, Araújo MJ, Aquino E, Kawachi I et al. Alcohol drinking patterns by gender, ethnicity, and social class in Bahia, Brazil. Rev Saude Publica. 2004;38(1):45-54.

36. Norman P, Conner MT, Stride CB. University students' reasons for binge drinking: An application of behavioural reasoning theory $\mathrm{Br} J$ Health Psychol. 2012;17(4):682-98. 
37. Tsakos G, Allen PF, Steele JG, Locker D. Interpreting oral health-related quality of life data. Community Dent Oral Epidemiol. 2012;40(3):193-200.

38. Batista M, Lawrence $H$, de Sousa M. Impact of tooth loss related to number and position on oral health quality of life among adults. Health Qual Life Outcomes. 2014;12:165. doi: 10.1186/ s12955-014-0165-5. 